\title{
Comparison between Natural Turf and Artificial Turf on Agility Performance of Rugby Union Players
}

\author{
Siu Ming Choi' ${ }^{1}$ Kim Wai Raymond Sum1, Fung Lin Elean Leung² \\ ${ }^{1}$ Department of Sports Science and Physical Education, Faculty of Education, The Chinese University of Hong \\ Kong, Hong Kong, China \\ ${ }^{2}$ Physical Education Unit, Faculty of Education, The Chinese University of Hong Kong, Hong Kong, China \\ Email: choisiuming@cuhk.edu.hk
}

Received 9 October 2015; accepted 27 November 2015; published 30 November 2015

Copyright (C) 2015 by authors and Scientific Research Publishing Inc.

This work is licensed under the Creative Commons Attribution International License (CC BY). http://creativecommons.org/licenses/by/4.0/

(c) (i) Open Access

\begin{abstract}
The purpose of this study was to investigate the difference in agility performance with natural turf (NT) and artificial turf (AT) surface in rugby union players on the repeated sprint, cut and turn movements and if any differences exist between holding the ball or not in relation to agility performance. Twelve tertiary rugby union players (mean \pm SD age, $21.2 \pm 2.0$ years) participated in the study. Players underwent measurements of anthropometry (height, body mass). Running tests investigated were 40-meter sprinting, change of direction, and "L" run, with all tests for agility measured in two sets with ball and without ball respectively. Results indicated that subjects showed significantly better overall agility performance $(P<0.05)$ in sprinting $(\mathrm{NT}$ : $6.40 \pm 0.26$ seconds, AT: $6.24 \pm 0.26$ seconds) and turning (NT: $6.40 \pm 0.44$ seconds, AT: $5.96 \pm 0.38$ seconds) on AT than NT. Although the time counted of cutting on AT was faster than on NT (NT: $13.85 \pm 0.61$ seconds, AT: $13.55 \pm 0.68$ seconds), the result was not significant. The findings also indicated that running with the ball for $\mathbf{4 0}$ meters would not slow the players down as there was a counter effect on the ground surface and ball carrying, while the turning movement was affected by both effects.
\end{abstract}

\section{Keywords}

Natural Turf, Artificial Turf, Agility Performance, Rugby Union Players

\section{Introduction}

Rugby union involves running, turning and cutting on footwork and it has been traditionally played on a surface

How to cite this paper: Choi, S. M., Sum, K. W. R., \& Leung, F. L. E. (2015). Comparison between Natural Turf and Artificial Turf on Agility Performance of Rugby Union Players. Advances in Physical Education, 5, 273-281.

http://dx.doi.org/10.4236/ape.2015.54032 
of natural turf (NT) (Fuller et al., 2010) at both competitive and recreational levels (Felipe et al., 2013). The development of artificial turf (AT) started in the 1960s (Pérez Soriano et al., 2009).

Fédération Internationale de Football Association (FIFA) and World Rugby (WR) took some action during the years from 2004 to 2008 respectively. In Regulation 22 of WR, there is a clear specification about the "Standard relating to the use of artificial playing surfaces". They both amended and published the changes, as well as the laws and regulations of the game for the allowance of the use of AT pitches. Establishment of appropriate quality standards for AT surfaces (Fuller et al., 2010; Müller et al., 2010) has also been stated together with the standards of correct maintenance of the surface, protection of the players' health and the environment and the anticipation of the low-cost policies (Felipe et al., 2013).

After the allowance to use AT pitches, and in some first-class and international competitions, AT has become a primary choice and is being widely used (Felipe et al., 2013). Substitution of NT pitches in bad condition generates higher economic, social and environmental returns and higher availability for use, in terms of hours per day and meteorological conditions. In times of inclement weather, the natural pitches may likely be closed but AT pitches may still be used as there is an ad hoc horizontal drainage system in place whereby the slopes can help water runoff into gutters around the edges (Zanetti et al., 2013). Since no puddles are formed, a match or training session can still be conducted normally when it rains. AT was originally designed to be used in dry conditions, but with the watering system, the turf could be moist. Current researches have also suggested that AT has become the most suitable surface for recreational sport as it provides much more use than NT and considerably reduces maintenance costs (Felipe, 2013; Zanetti et al., 2013). As the AT has a shorter closing period for maintenance, compared with NT which requires tilling, planting, watering and spraying pesticides, people can appropriate the increased usage time for their physical activities.

Conducting rugby activities on AT has some effects on the increase in friction and decrease in impact absorption on the biomechanical relationship between the power exerted by the player and the ground surface. In addition, since AT is technologically well-built using engineering and machinery, there is an absence of the need for adjustment in the irregularities of NT for the players (Pérez Soriano et al., 2009). Therefore, they can run and sprint faster on AT. On the other hand, the cutting speed during a one-off sprint is also faster on AT than on NT because more force is being exerted during the change-in-direction motion (Gains et al., 2010; Nédélec et al., 2013). Thus, previous researches have shown that AT can provide ground for players to run faster.

The sport of rugby not only requires speed and agility, but this is also combined with other aspects, particularly carrying the rugby ball. Meir et al. (2013) emphasized that the factor of carrying a ball on the agility test and performance is often neglected. When the subjects did the movements with a ball, arm movement would be restricted and affect the force being exerted from swinging arms, and eventually reduce the balancing performance and ground contact force. There were some previous studies investigating 30 meters of sprinting with and without a ball although they did not apply the same methodology (Walsh et al., 2007). Therefore, this study also compares the agility performance with and without the rugby ball of the player.

This investigation sets out to examine the best agility performance on different surfaces by rugby union players. They can devise tactics for different surfaces. When facing the defenders, the players have to decide whether to run through the gaps, to gain yards by smashing the defense line or to simply pass the ball. On a higher level, players need to decide what tactics to apply more; cutting, blocking (the changing angle is less than 90 degrees) or lopping (the changing angle is more than 90 degrees), on the AT. Coaches and teams can use the results to analyze what tactics they should adopt on different types of surfaces.

Current research focuses on the biomechanical and sports injuries in team sports played on AT compared with those on NT in soccer, hockey and American football but there is a lack of information available on performance, and none is specifically for rugby union. In order to find out which surfaces could provide the ground for the players to exert their best performance, the purpose of this research was to investigate the difference of agility performance on NT and AT surfaces by rugby union players on the repeated sprint, cut and turn movements. Further study was to investigate whether the subjects holding the ball would affect the agility performance or not. The research hypothesis is that the performance on repeated sprinting, cutting and turning movement is better on AT than that of NT.

\section{Methodology}

\subsection{Sample}

A total of 12 healthy and physically-active, male, tertiary rugby union players participated voluntarily in the 
study. The participants are currently training and competing regularly on NT and AT. They are all competing at tertiary level or above, i.e. semi-professional level, in Hong Kong competitions. All of them were informed of the study requirements, benefits and risks by giving informed consent before the agility performance test. Mean characteristics of samples can be seen in Table 1 .

\subsection{Turf Sample}

Two turf samples (one AT and one NT) were selected for the study. The NT sample was used when the subjects went for practice sessions where as the AT sample was used when the subjects had competitions. Both turfs were reconstructed half a year before the agility performance test was carried out. Table 2 shows the characteristics and comparisons of the two turf samples. As there is no synthetic infill on NT, thus the information on that is not available (N/A).

\subsection{Procedures}

All subjects took part in 2 trials, one on AT and one on NT (with a 7-dayinterval between trials). Standardized warm-ups (15 minutes) were carried out, including 5 minutes jogging, followed by a schema of dynamic stretching such as buttock kicks, high knee lifts, backwards running, sidestepping and progressive sprinting exercise. Also, a jogging run test was undertaken to minimize the running direction error of the participants. The warm-up was aimed only at preparing the participants for the agility test and was not intended for them to exert all their power, force and strength.

Three agility performance tests with four trials ( 2 trials with balls and 2 trials without balls) on each test were used. On each attempt, approximately 2 - 3 minutes of rest provided ground for subjects to recover (Yasuda et al., 2011). In this study, digital hand-held stop watch is used to measure the time of recovery. Each trial had two minutes of interval rest and there were five minutes of interval rest between each test.

The first test was the sprint test in which the participants were instructed to sprint 40 meters from a standing start (Zanetti et al., 2013; Müller et al., 2010; Hughes et al., 2013).

The second test was the change of direction speed test. For the test settings, tapes and cones were placed on the floor to guide and facilitate a sharp 72 degree cut. Subjects sprinted forward $5 \mathrm{~m}$ and then changed direction according to the cones. The test involved 11 cutting and 12 acceleration movements in 26 meters from a standing start (Green et al., 2009; Zanetti et al., 2013).

Table 1. Mean ( \pm S.D.) characteristics of samples.

\begin{tabular}{cccc}
\hline Age (years) & Height $(\mathrm{cm})$ & Body Weight $(\mathrm{kg})$ & Experience (years) \\
\hline $21.2( \pm 2.0)$ & $175.6( \pm 8.0)$ & $70.9( \pm 9.0)$ & $3.6( \pm 2.4)$ \\
\hline
\end{tabular}

Table 2. Characteristics of turf samples.

\begin{tabular}{|c|c|c|c|}
\hline & & NT & $\mathrm{AT}$ \\
\hline \multirow[t]{4}{*}{ Grass } & Material & Zoysia matrella & Polyethylene monofilament \\
\hline & Weight/Length (tex) & N/A & 1300 \\
\hline & Stitch rate (pt./mm) & $\mathrm{N} / \mathrm{A}$ & 20 \\
\hline & Pile Length(mm) & 30 & 60 \\
\hline \multirow[t]{2}{*}{ Sand } & Granulometry (mm) & $<1$ & $0.63-1.25$ \\
\hline & Weight/Area $\left(\mathrm{kg} / \mathrm{m}^{2}\right)$ & 300 & 30 \\
\hline \multirow[t]{4}{*}{ Synthetic Infill } & Material & N/A & Styrene Butadiene Rubber (SBR) \\
\hline & Granulometry (mm) & $\mathrm{N} / \mathrm{A}$ & $0.8-2.5$ \\
\hline & Weight/Area $\left(\mathrm{kg} / \mathrm{m}^{2}\right)$ & $\mathrm{N} / \mathrm{A}$ & 12 \\
\hline & Shape & $\mathrm{N} / \mathrm{A}$ & Angular \\
\hline Shock-pad & / & $\mathrm{N} / \mathrm{A}$ & Stockmeier in situ (25 mm) \\
\hline
\end{tabular}


The third test was the "L" run and was set up by 3 taped cones which were placed 5 meters apart in the shape of an "L". It involved two 90 degree turnings, one 180 degree turning and 4 acceleration movements in 20 meters from a standing start (Gabbett et al., 2008).

Müller et al. (2010) mentioned that "Running performance testing allows investigating the functionality of traction characteristics by quantifying the direct time benefit for players". Time result was counted from every trial in 3 tests. To facilitate measuring the results, the times were counted by an experienced hand timer using a digital hand-held stop watch which can measure time to the nearest 0.01 second. The starting and finishing line were marked by cones. The position of the timer was standing perpendicular to the finishing line. The stopwatch was started to count time when the subjects passed the starting line and stopped when they crossed the finishing line.

All tests required participants to run as fast as possible. For the change of direction movement, the angle was smaller than 90 degrees, and participants were required to have a one-off cut rather a turn with a few small steps. For the turning movement with more than 90 degrees, the subjects should use a few small steps to change their direction. Also, it was necessary to carry a ball in both hands in the specified trials. The above mentioned requirements were devised in order to reduce errors in all tests.

\subsection{Data Analysis}

Data was analyzed by SPSS software. The mean $+/-$ standard deviation and range of the age, height, weight, and time counted in the test was investigated. Paired sample t-tests were used for 1) NT and AT comparison and 2) trials with and without ball. Two sets of data were investigated in order to find out the significant differences between them. The data were then divided into four sets as shown in the table below in order to investigate whether the subjects could carry out the same agility performance with a rugby ball in the test. Combinations between different sets of data can be seen in Table 3.

Confidence level was set at $95 \%(P \leq 0.05)$ to maintain statistical reliability and validity for all analysis. If $P$ $\geq 0.05$, it was considered as unclear or insignificant in the comparison.

\section{Results}

\subsection{Overall Agility Performance}

It was shown that the overall agility performance was significantly $(P<0.05)$ better on AT than that on NT in the 40-meter sprinting test (2.4497\%) and "L" run test (6.8726\%). However, there was no difference $(P>0.05)$ in the change of direction speed test (2.1482\%) although the time counted was faster on AT than that of NT. The present result suggests that the sprinting and turning performance is better on AT than that of NT while the cutting performance remains unaffected.

After the performance of overall agility test had been viewed, the comparison of each combination on each test between sets of data results as shown in Table 3, i.e. NT versus AT and carrying with ball versus without ball were investigated. Mean times for all tests and combinations can be seen in Table 4 .

\subsection{0-Meter Sprinting Test}

The time count result on AT was better than that of NT in the 40-meter sprinting test among all combinations. Percentage difference in combination D (3.8053\%) was the greatest among all combinations while combination A, B and C were $2.8353 \%, 2.0679 \%$ and1.0804\% respectively. There was no difference $(P>0.05)$ on combination $\mathrm{C}$, the comparison of sprinting on NT without ball versus that of AT with ball. In the remaining combinations, sprinting on AT was significantly better $(P<0.05)$ than that on NT, especially in combination D, sprinting on NT with ball (6.43 \pm 0.28 seconds) versus that on AT without ball (6.18 \pm 0.28 seconds). Mean times for all conditions can be seen in Figure 1.

Table 3. Combination between different sets of data.

\section{NT vs AT (in total)}
A. NT without ball vs AT without ball
B. NT with ball vs AT with ball
C. NT without ball vs AT with ball
D. NT with ball vs AT without ball 


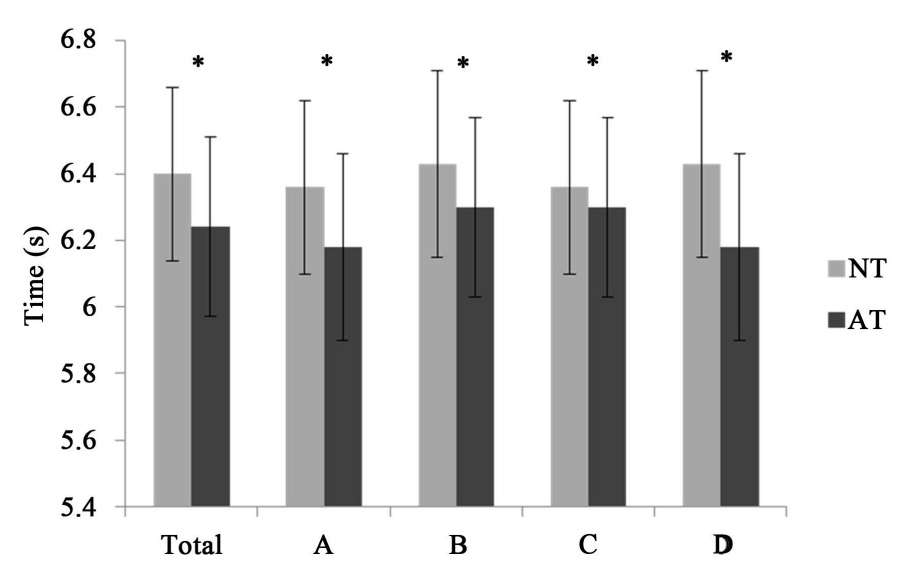

Figure 1. Mean Time (in seconds, s) for the Agility performance on 40meter Sprinting Test between NT and AT. ${ }^{*}$ Difference between tests $(P<$ 0.05). Error Bars denote one standard deviation around mean.

Table 4. Mean time (in seconds, s) for the agility performance between natural turf and artificial turf $(\mathrm{n}=12)$.

\begin{tabular}{|c|c|c|c|c|c|c|c|}
\hline & \multirow[b]{2}{*}{ Combinations } & \multicolumn{2}{|c|}{ 40-meter Sprinting } & \multicolumn{2}{|c|}{ Change of direction } & \multicolumn{2}{|c|}{ "L” run } \\
\hline & & Mean ( \pm S.D.) & $\begin{array}{c}\text { Sig. } \\
\text { (2-tailed) }\end{array}$ & Mean ( \pm S.D.) & $\begin{array}{c}\text { Sig. } \\
\text { (2-tailed) }\end{array}$ & Mean ( \pm S.D.) & $\begin{array}{c}\text { Sig. } \\
\text { (2-tailed) }\end{array}$ \\
\hline & $\begin{array}{l}\text { Total NT vs } \\
\text { Total AT }\end{array}$ & $\begin{array}{l}6.40( \pm 0.26) \\
6.24( \pm 0.27)\end{array}$ & 0.003 & $\begin{array}{l}13.85( \pm 0.61) \\
13.55( \pm 0.68)\end{array}$ & 0.152 & $\begin{array}{l}6.40( \pm 0.44) \\
5.96( \pm 0.38)\end{array}$ & 0.000 \\
\hline A & $\begin{array}{c}\text { No-ball NT vs } \\
\text { No-ball AT }\end{array}$ & $\begin{array}{l}6.36( \pm 0.26) \\
6.18( \pm 0.28)\end{array}$ & 0.003 & $\begin{array}{l}13.89( \pm 0.64) \\
13.53( \pm 0.61)\end{array}$ & 0.117 & $\begin{array}{l}6.39( \pm 0.47) \\
5.98( \pm 0.40)\end{array}$ & 0.000 \\
\hline B & $\begin{array}{l}\text { Ball NT vs } \\
\text { Ball AT }\end{array}$ & $\begin{array}{l}6.43( \pm 0.28) \\
6.30( \pm 0.27)\end{array}$ & 0.029 & $\begin{array}{l}13.81( \pm 0.69) \\
13.58( \pm 0.79)\end{array}$ & 0.333 & $\begin{array}{l}6.41( \pm 0.42) \\
5.94( \pm 0.38)\end{array}$ & 0.001 \\
\hline $\mathrm{C}$ & $\begin{array}{c}\text { No-ball NT vs } \\
\text { Ball AT }\end{array}$ & $\begin{array}{l}6.36( \pm 0.26) \\
6.30( \pm 0.27)\end{array}$ & 0.200 & $\begin{array}{l}13.89( \pm 0.64) \\
13.58( \pm 0.79)\end{array}$ & 0.169 & $\begin{array}{l}6.39( \pm 0.47) \\
5.94( \pm 0.37)\end{array}$ & 0.001 \\
\hline $\mathrm{D}$ & $\begin{array}{l}\text { Ball NT vs } \\
\text { No-ball AT }\end{array}$ & $\begin{array}{l}6.43( \pm 0.28) \\
6.18( \pm 0.28)\end{array}$ & 0.001 & $\begin{array}{l}13.81( \pm 0.69) \\
13.53( \pm 0.61)\end{array}$ & 0.195 & $\begin{array}{l}6.41( \pm 0.42) \\
5.98( \pm 0.40)\end{array}$ & 0.000 \\
\hline
\end{tabular}

\subsection{Change of Direction Speed Test}

The time count result on AT was better than that of NT in the change of direction speed test. Percentage difference in combination A (2.6246\%) was the greatest among all combinations while B was $1.6688 \%$, C was $2.2617 \%$ and D was $2.0340 \%$ respectively. However, all cutting movement combinations were not significantly better ( $P$ > 0.05) on AT than that on NT. Mean times for all conditions can be seen in Figure 2.

\section{4. "L" Run Test}

The time count result on AT was better than that of NT in the "L" run test. Percentage difference in combination B (7.3318\%) was the greatest among all combinations while A was $6.4118 \%$, C was $7.0054 \%$ and D was $6.7403 \%$ respectively. All turning movement combinations were significantly better $(P<0.05)$ on AT than those on NT, especially the combination of comparing NT with ball versus AT with ball. Mean times for all conditions can be seen in Figure 3. 


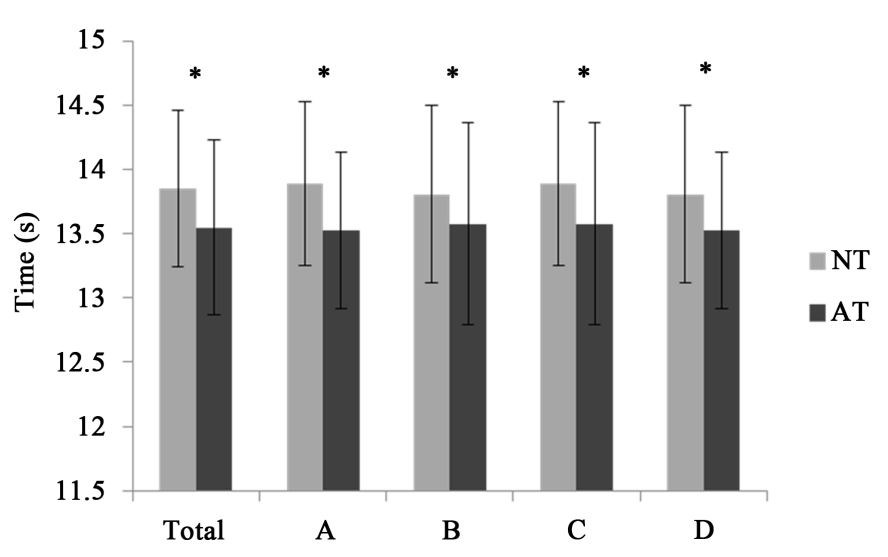

Figure 2. Mean time (in seconds, s) for the agility performance on change of direction test between NT and AT. *Difference between tests $(P<0.05)$. Error Bars denote one standard deviation around mean.

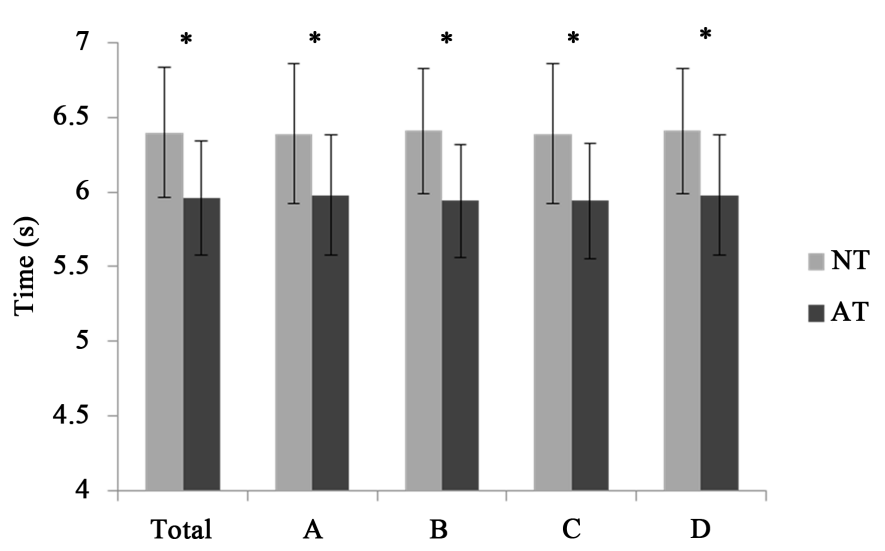

Figure 3. Mean Time (in seconds, s) for the Agility performance on "L" RunTest between NT and AT. *Difference between tests $(P<0.05)$. Error Bars denote one standard deviation around mean.

\section{Discussion}

The findings from the present study support the hypothesis that rugby union players agility performance on AT is better than that on NT. This statement is not only based on the time count result, but the data is also significant on the sprinting movement in the 40-meter test and turning movement in " $\mathrm{L}$ " run test while the cutting movement in change in direction test is insignificant. By comparing the trials with and without ball, the present study has shown that the agility performance test is affected by ground surface and the situation ball carrying effect. The results show that players' 40-meter sprinting performance was not affected by carrying balls which means that the ground surface effect is larger than the ball carrying effect while the turning movement in " $L$ " test is affected by both effects.

\subsection{Overall Agility Performance}

There are different definitions on versions and types of agility in many literatures. Meir et al. (2013) and Jarvis et al. (2009) defined that agility is the combination of physical demands (strength and conditioning), cognitive processes (motor learning) and technical skills (biomechanics). Agility is also defined as the whole body producing rapid change of direction and speed movement in response to a sport-specific stimulus. It is noted that biomechanics is one of the aspects with respect to the technical skills in agility, and the difference in the playing surface is thus a crucial factor affecting agility performance. The present findings showed that agility performance, especially sprinting and turning, is better on AT than on NT. It matches the biomechanical relationship of 
the increase in fiction and decrease in impact absorption, which is the power produced from the subjects with AT which does not have the irregularities that NT has (Pérez Soriano et al., 2009) no matter whether players are carrying the ball or not. Therefore, when the athletes run on AT with sprinting and turning, they can run more smoothly than on NT. AT can provide ground for them to have a better agility performance to produce side-step movement and footwork in defense. In other words, AT has the ground surface effect to improve all-round rugby performance.

\subsection{Ball-Carrying Agility Performance}

The ball can be carried by either both hands or under one arm in rugby. Although running with carrying the ball under one arm is faster than that of both hands, rugby is not a sport where one only competes in terms of speed. The more important aspects are to keep possession and continuity of play (Walsh et al., 2007). The reason for carrying using two hands in the test is to provide an extra choice for the player to pass the ball in a more stable way, which is closer to the real situation.

As mentioned from the previous studies, running with a ball restricts the arm swinging movement which negatively affects the force exerted, balance performance and ground contact force (Walsh et al., 2007). The findings in the present study partly supported the above statements as the performance while in possession of the ball is significantly slower when compared to that without the ball in sprinting and turning movement $(P<0.05)$ by only focusing on the ball carrying effect. On the other hand, we should also focus on the ground surface effect in the sense that both effects can affect the agility performance of the rugby union players.

\subsubsection{0-Meter Sprinting Test}

The greatest percentage difference combination is D (NT with ball versus AT without ball). This is due to a combined effect of ground surface effect and ball carrying effect. In combination A (NT versus AT without ball) and B (NT versus AT with ball), the present findings focus on one variable that is ground surface effect while the ball carrying effect remains unchanged. On the other hand, an insignificant result is generated for combination C (NT without ball versus AT with ball), when considering both ground surface effect (AT is better than NT) and ball carrying effect (running without a ball is better than that with a ball). The result of combination C will be ambiguous as it is insignificant in the sense that the ground surface effect may offset the ball carrying effect, and vice versa. With the significant support from combination A and B while combination C is insignificant in the difference, the result is consistent with combination $\mathrm{D}$.

\subsection{2. "L" Run Test}

In the "L" run test, although the greatest percentage difference combination is B (NT versus AT with ball), the percentage difference in remaining combinations is similar among them (within 1\%). The possible explanation for similar results is that there is a double effect on surface effect and ball carrying effect as the running distance and method are different from the sprinting test and change of direction test. Subjects had to run a distance of 20 meters with 3 turning movements every 5 meters in the " $\mathrm{"}$ " run test. During the sprinting after the turning, the athlete may not be at a higher speed when carrying the ball with both hands. It produces a counter effect on turning force at the hip joint in this short distance (Walsh et al., 2007). Together with the surface effect, the percentage difference between AT and NT is $6.4 \%-7.3 \%$, which is much more than the sprinting and cutting movement.

\subsubsection{Change of Direction Speed Test}

The result of change of direction test did not show a clear finding although the speed on the AT was faster than that on the NT. Previous research found that there is little or no relationship between straight sprinting and sprinting with change of direction (Sheppard \& Young, 2006). The possible reason for the insignificant result in the present study is that some subjects did not step outside the cone but over the cone which may cause error.

\section{Limitations}

The improvements in the agility test in this study were not due to the learning effect for the following reason: subjects were randomly assigned to one of the turfs; some of them had the test on artificial turf first, and one week later they were on natural turf; others were vice versa. 
There are previous researches supporting that the physiological performance and some aspects of anthropometric differences such as speed, repeated sprint ability are evident when comparing between forwards and backs (Jarvis et al., 2009). Therefore, this research focused on 7-a-side rugby players as there is a huge difference in speed and agility performance in 15-a-side rugby between forward and backs. Therefore, the limitation is that the subjects are mainly male and 7-a-side rugby union players in order to minimize the effect.

To avoid having the subject run outside of the cones in the change of direction test, further study can use traffic cones and count how many cones the subjects have kicked down or use life-sized cardboard as the marks and barriers which can test their cutting movement of agility performance.

Another limitation is that every single participant used different types of boots in the trial. This research suggested that they wear the boots which they always use in order to minimize the uncomfortable effect in the test.

\section{Conclusion and Future Study}

The decision on using NT or AT in the field has always been a debate for the government, public and the sports association with respect to the management and maintenance of the turf. With technology improvement and the inclusion of new material, AT had become popular nowadays although previous studies mentioned that early generation AT would cause more injuries (Pérez Soriano et al., 2009). This study focuses on the agility performance in sprinting, cutting and turning movements. With 3 agility tests, the results of this study show that the sprinting and turning movement is significantly better on AT than on NT as the subjects can generate more force from the surface. When comparing the trials with and without the ball, this study can have a deeper investigation and show that holding a ball while sprinting 40 meters cannot slow the player while there is a double slowing effect, i.e. surface and holding ball, on the turning movement when running on NT.

Furthermore, reactive agility speed test can also be added to investigate the relationship between the surface and reaction time of the subjects. Reactive agility is a newly introduced concept which is one of the broad types of agility together with the change of direction speed. Meir et al. (2013) mentioned that reactive agility "includes physical and cognitive component that requires the athlete to react to some form of visual and or aural stimulus". For the test, the subjects would sprint 10 meters first and then react to the flashing gate and change direction 45 degrees to run 10 meters more through the finish gate (Green et al., 2009; Meir et al., 2013). The advantage of this test is that the further studies can let us know more about the effect of agility with different stimulation on NT and AT.

\section{References}

Felipe, J. L., Gallardo, L., Burillo, P., \& Gallardo, A. (2013). A Qualitative Vision Artificial Turf Football Fields: Elite Players and Coaches.South African Journal for Research in Sport, Physical Education and Recreation, 35, 105-120.

Fuller, C. W., Clarke, L., \& Molloy, M. G. (2010). Risk of Injury Associated with Rugby Union Played on Artificial Turf. Journal of sports sciences, 28, 563-570. http://dx.doi.org/10.1080/02640411003629681

Gabbett, T. J., Kelly, J. N., \& Sheppard, J. M. (2008). Speed, Change of Direction Speed, and Reactive Agility of Rugby League Players. The Journal of Strength \& Conditioning Research, 22, 174-181. http://dx.doi.org/10.1519/JSC.0b013e31815ef700

Gains, G. L., Swedenhjelm, A. N., Mayhew, J. L., Bird, H. M., \& Houser, J. J. (2010). Comparison of Speed and Agility Performance of College Football Players on Field Turf and Natural Grass. The Journal of Strength \& Conditioning Research, 24, 2613-2617. http://dx.doi.org/10.1519/JSC.0b013e3181eccdf8

Green, B., Blake, C., \& Caulfield, B. (2009). Field Testing to Predict Performance in Rugby Union Players. ISBS-Conference Proceedings Archive, 1, No. 1.

Hughes, M. G., Birdsey, L., Meyers, R., Newcombe, D., Oliver, J. L., Smith, P. M., \& Kerwin, D. G. (2013). Effects of Playing Surface on Physiological Responses and Performance Variables in a Controlled Football Simulation. Journal of Sports Sciences, 31, 878-886. http://dx.doi.org/10.1080/02640414.2012.757340

Jarvis, S., Sullivan, L. O., Davies, B., Wiltshire, H., \& Baker, J. S. (2009). Interrelationships between Measured Running Intensities and Agility Performance in Subelite Rugby Union Players. Research in Sports Medicine, 17, 217-230. http://dx.doi.org/10.1080/15438620903323892

Meir, R. A., Holding, R., Hetherington, J., \& Rolfe, M. I. (2013). Impact of Sport Specific and Generic Visual Stimulus on a Reactive Agility Test while Carrying a Rugby Ball. Journal of Australian Strength and Conditioning, 21, 45.

Müller, C., Sterzing, T., Lange, J., \& Milani, T. L. (2010). Comprehensive Evaluation of Player-Surface Interaction on Ar- 
tificial Soccer Turf. Sports Biomechanics, 9, 193-205. http://dx.doi.org/10.1080/14763141.2010.511679

Nédélec, M., McCall, A., Carling, C., Le Gall, F., Berthoin, S., \& Dupont, G. (2013). Physical Performance and Subjective Ratings after a Soccer-Specific Exercise Simulation: Comparison of Natural Grass versus Artificial Turf. Journal of Sports Sciences, 31, 529-536. http://dx.doi.org/10.1080/02640414.2012.738923

Pérez Soriano, P., LlanaBelloch, S., CortellTormo, J. M., \& Pérez Turpin, J. A. (2009). Biomechanical Factors to Be Taken into Account to Prevent Injuries and Improve Sporting Performance on Artificial Turf.

Sheppard, J. M., \& Young, W. B. (2006). Agility Literature Review: Classifications, Training and Testing. Journal of Sports Science, 24, 919-932. http://dx.doi.org/10.1080/02640410500457109

Walsh, M., Young, B., Hill, B., Kittredge, K., \& Horn, T. (2007). The Effect of Ball-Carrying Technique and Experience on Sprinting in Rugby Union. Journal of Sports Sciences, 25, 185-192. http://dx.doi.org/10.1080/02640410600630571

Yasuda, T., Ogasawara, R., Sakamaki, M., Ozaki, H., Sato, Y., \& Abe, T. (2011). Combined Effects of Low-Intensity Blood Flow Restriction Training and High-Intensity Resistance Training on Muscle Strength and Size. European Journal of Applied Physiology, 111, 2525-2533. http://dx.doi.org/10.1007/s00421-011-1873-8

Zanetti, E. M., Bignardi, C., Franceschini, G., \& Audenino, A. L. (2013). Amateur Football Pitches: Mechanical Properties of the Natural Ground and of Different Artificial Turf Infills and Their Biomechanical Implications. Journal of Sports Sciences, 31, 767-778. http://dx.doi.org/10.1080/02640414.2012.750005 